\title{
The Effects of Urban Green Space on Depressive Symptoms of Mid-Aged and Elderly Urban Residents in China: Evidence from the China Health and Retirement Longitudinal Study
}

\author{
Rui Zhou ${ }^{\dagger}$, Ying-Jing Zheng ${ }^{\dagger}$, Jing-Yi Yun and Hong-Mei Wang *(B)
}

Citation: Zhou, R.; Zheng, Y.-J.; Yun, J.-Y.; Wang, H.-M. The Effects of Urban Green Space on Depressive Symptoms of Mid-Aged and Elderly Urban Residents in China: Evidence from the China Health and Retirement Longitudinal Study. Int. J Environ. Res. Public Health 2022, 19, 717. https://doi.org/10.3390/ ijerph19020717

Academic Editors: Xinbin Feng and Paul B. Tchounwou

Received: 11 November 2021

Accepted: 6 January 2022

Published: 10 January 2022

Publisher's Note: MDPI stays neutral with regard to jurisdictional claims in published maps and institutional affiliations.

Copyright: (C) 2022 by the authors. Licensee MDPI, Basel, Switzerland. This article is an open access article distributed under the terms and conditions of the Creative Commons Attribution (CC BY) license (https:// creativecommons.org/licenses/by/ $4.0 /)$.

\author{
Department of Social Medicine of School of Public Health, and Department of Pharmacy of the First Affiliated \\ Hospital, School of Medicine, Zhejiang University, Hangzhou 310058, China; zhou_rui@zju.edu.cn (R.Z.); \\ zhengyingjing@zju.edu.cn (Y.-J.Z.); xyun@zju.edu.cn (J.-Y.Y.) \\ * Correspondence: rosa@zju.edu.cn \\ † These authors have contributed equally to this work.
}

\begin{abstract}
The aim of this study is to assess the impacts of urban green space on depressive symptoms among Chinese urban residents aged 45 and older. In total, 7397 urban respondents were included in this study. Each respondent participated in the China Health and Retirement Longitudinal Study Wave 3 (2015). Environmental-level variables were retrieved from the National Bureau of Statistics database. Both unadjusted and adjusted methods were used in the multilevel regression analysis. Almost one-third of the sample population suffered from depressive symptoms (31.20\%). The multilevel logistic regression model showed that green coverage ratio of city-built districts is negatively associated with the prevalence of depressive symptoms among urban mid-aged $(\mathrm{OR}=0.79$, $p<0.05)$ and elderly $(\mathrm{OR}=0.75, p<0.05)$ residents, and the public recreational green space helps to reduce elderly people's depressive symptoms $(\mathrm{OR}=0.77, p<0.05)$. This study adds insights about the impact of green space and other environmental factors on depressive symptoms among mid-aged and elderly urban dwellers. It is important to provide enough and accessible overall urban green spaces; additionally, attention should also be paid to specific green space forms such as public recreational green space.
\end{abstract}

Keywords: depression; green space; mid-aged and elderly; China

\section{Introduction}

Depression, one of the most common mental disorders in many countries, affects approximately $7 \%$ of the elderly population worldwide [1]. The situation among the midaged population is also not optimistic; prevalence of depression among females and males aged $45-59$ is more than $7 \%$ and 5\%, respectively [2]. Depression contributes greatly to daily function impairment and increases the suicide rate $[3,4]$. There is some evidence to suggest that prevalence of depressive disorders among urban residents in high-income countries is higher than their rural counterparts [5,6]. Although the situation in China has been reported to be exactly the opposite $[7,8]$, the rate of depressive symptoms among Chinese urban populations is dramatically higher than in other low- and middle-income countries and Asian countries [9-11]. China has about $60 \%$ of its population living in urban areas in 2018 [12], and the percentage of the elderly population living in cities rose from $26.3 \%$ in 2006 to $52.0 \%$ in 2015 [13,14]. Therefore, the depressive problems of urban residents also need particular attention in China.

Existing studies have found a high rate of depressive symptoms among mid-aged and elderly population in China and explored the association between depression and individual-level factors such as gender, income, health status, and financial transfers $[7,8,15,16]$, while it is increasingly important to explore environmental risk factors for this major mental health issue against the backdrop of urbanization [17]. 
Previous studies initially focused on urban environment and mental health have reported that denser urban population [18] and exposure to noise pollution [19] and air pollution [20] were related to increased depressive symptoms. Furthermore, exposure to natural environment including parks and other green spaces seems to play a positive role in relieving depression of urban residents [11,21]. Natural green resources can help improve mental health by encouraging physical activity [22] and social interaction [23]. The relations between green space and mental health can vary with availability, typology, and several other aspects of green space [24,25]. Specific types of green space may be more strongly associated with health outcomes than overall quantity of green space [26], and health effects could differ by type of green space; for example, trees were found to have superior benefits than grassland in improving mental health [27]. However, previous studies in this field usually concern people of all ages [28,29], youth [30-33], university students [34-36], or patients with specific diseases [37-39], while only limited researches focus on mid-aged and elderly urban residents [11,40]. Moreover, most studies have been conducted in several developed countries, while little attention has been paid to the context of developing countries with undergoing rapid urbanization such as China.

This study will investigate the association between urban green space and depressive symptoms among urban mid-aged and elderly residents in China, hoping to provide evidence for the formulation of effective policies to cope with urbanization and population aging. The mid-aged and the elderly are both at high risk of developing depressive symptoms. Meanwhile, there could be substantial differences in activity patterns and interaction with the environment in adults at different life stages [41-43], the impacts of green space may also vary across age groups. Therefore, our study included both the midaged and the elderly respondents and described the impacts of green space on respondents of different age ranges, respectively. For older citizens, prior studies emphasized park as a special type of urban green space [40], and immediate surroundings with greenery are vital for the elderly if they experience physical health problems [44,45]. We therefore examined per capita public recreational green space (including park) and the proportion of green coverage area in the total area of city-built districts in this study.

\section{Materials and Methods}

\subsection{Study Design}

This study was a secondary analysis of data collected from the China Health and Retirement Longitudinal Study (CHARLS) Wave 3 (2015). The data and relevant files can be found in the China Health and Retirement Longitudinal Study official website repository, http: / / charls.pku.edu.cn/index/zh-cn.html (accessed on 10 December 2019). The CHARLS is a cross-national, population-based research project exploring extensive topics related to health and socioeconomic status among people aged 45 and older in China. A multi-stage stratified probability proportional to size (PPS) sampling design was employed to select respondents from 450 villages in 150 county-level units of 28 provinces in China. The baseline survey was launched in 2011-2012 and follow-up surveys were conducted every two or three years. The CHARLS was conducted according to the guidelines of the Declaration of Helsinki and approved by the Institutional Review Board at Peking University (IRB00001052-11015). Further detailed descriptions of CHARLS have been published elsewhere $[20,46,47]$. The variable community ID recorded respondents' household living regions at the community level, based on which the CHARLS classified respondents' places of residence into urban and rural according to National Bureau of Statistics of the People's Republic of China. We restricted the sample to people aged 45 and older living in urban areas and having full information on the included variables, resulting in a sample size of 7397 respondents from 213 neighborhoods nested within 103 cities, among which there were 3814 mid-aged people aged between 45 and 59 and 3583 elderly people aged 60 and older.

Depressive symptoms were measured by the 10-item short form of the Center for Epidemiological Studies-Depression Scale (CESD-10) in CHARLS. All items are rated on 
a four-point Likert scale ranging from 0 (rarely or none of the time) to 3 (most or all of the time). The total score values range from 0 to 30 , with higher scores indicating greater depressive symptoms, and a score of 10 or higher was used as a cut-off point for depressive symptoms [48]. CESD-10 has been proved to have adequate psychometric properties elsewhere [49]. A Cronbach's alpha coefficient value of 0.71 was found for the scale in this study.

\subsection{Measures}

\subsubsection{Explanatory Variables}

Urban green space is defined as including parks, affiliated green space, production green space, protective green space, etc. [36,50] To assess the amount of green space, we selected two existing city-level variables: one is the per capita public recreational green space ( $\mathrm{m}^{2} /$ person) for entertainment, sports, and social interaction, and the other one is the proportion of green coverage area that represents the overall green coverage in the total area of city built districts (hectares $/ \mathrm{Km}^{2}$ ). These data were derived from the 2015 China Urban Construction Statistical Yearbook [50]. Following the approach described in other similar studies [51-53], the two explanatory variables were divided into three levels using tertiles (Table 1). Details of the three levels are as follows: (1) per capita public recreational green space-low level: 6.98-14.90 $\mathrm{m}^{2}$ /person; medium level: $15.07-19.85 \mathrm{~m}^{2} /$ person; high level: $21.82-38.11 \mathrm{~m}^{2} /$ person, (2) green coverage area in built up area of citylow level: 18.14-37.67 hectare $/ \mathrm{Km}^{2}$; medium level: 38.03-42.95 hectare $/ \mathrm{Km}^{2}$; high level: 43.33-52.02 hectare $/ \mathrm{Km}^{2}$.

Table 1. Descriptive statistics of urban green space indicators.

\begin{tabular}{|c|c|c|c|c|c|c|}
\hline \multirow[t]{2}{*}{ Category } & \multicolumn{3}{|c|}{$\begin{array}{l}\text { Per Capita Public Recreational Green Space } \\
\qquad\left(\mathrm{m}^{2} / \text { person }\right)\end{array}$} & \multicolumn{3}{|c|}{$\begin{array}{c}\text { Green Coverage Area in Built Up Area of City } \\
\left.\text { (hectare/(Km }{ }^{2}\right)\end{array}$} \\
\hline & Mean (SD) & Min & $\operatorname{Max}$ & Mean (SD) & Min & Max \\
\hline Low Level & $11.45( \pm 2.12)$ & 6.98 & 14.90 & $33.35( \pm 4.48)$ & 18.14 & 37.67 \\
\hline Medium Level & $17.27( \pm 1.48)$ & 15.07 & 19.85 & $40.12( \pm 1.18)$ & 38.03 & 42.95 \\
\hline High Level & $25.53( \pm 5.50)$ & 21.82 & 38.11 & $45.82( \pm 2.55)$ & 43.33 & 52.02 \\
\hline Total & $13.52( \pm 4.50)$ & 6.98 & 38.11 & $39.78( \pm 4.76)$ & 18.14 & 52.02 \\
\hline
\end{tabular}

\subsubsection{Control Variables}

Age, gender, marital status, education, and work were included as demographic variables. Participants were divided into two age groups: $45-59$ and 60 and above. Marital status was grouped as being married or cohabitated versus separated, divorced, widowed, or never married. Education was categorized as primary education or below, middle school, senior high school, and associate degree or above. Based on a series of questions about job status, the variable work was generated as a binary variable indicating whether the respondents had a job at the time of survey.

Co-morbidity condition, physical function, and participation of outdoor activity were included as health-related factors. Respondents were asked if they had been diagnosed with any of the listed 14 chronic diseases, and co-morbidity was grouped as having no disease, suffering from one disease, or having co-morbidity. Physical function was measured by a short version of Instrumental Activities of Daily Life Scale (IADL). The short form consists of six items, and all items are rated on a four-point scale ranging from 1 (having no difficulty) to 4 (cannot do it); people who scored higher than 6 had a different degree of physical function damage [54]. Internal consistency for this short form measured by Cronbach's $\alpha$ was 0.84 . Participation of outdoor activity was grouped as yes or no to the question "Have you participated in activities such as dancing, exercising, etc., in the last month?" [55].

City type, city GDP (billion RMB), and population density (persons $/ \mathrm{Km}^{2}$ ) were involved as city-level environmental control variables, which have been proved associated 
with urban green space [56-58]. In this study, the city was categorized by administrative hierarchy into four types: municipality directly under the central government, vice-provincial city, prefecture-level city, and county-level city. Development of a city can be closely associated with its administrative level. Cities with higher administrative level tend to be larger, more prosperous, and at advantage of resource allocation [59]. The city GDP (billion $\mathrm{RMB}$ ) and population density (persons $/ \mathrm{Km}^{2}$ ) can be obtained from the 2016 China City Statistical Yearbook and the 2015 China Urban Construction Statistical Yearbook.

\subsection{Statistical Analysis}

In this study, people aged between 45-59 and those aged 60 and older were analyzed, respectively. Descriptive analysis was used to give a general overview of respondents' characteristics; the results were presented in the form of percentage for categorical variables and means and standard deviation (SD) for continuous variables. Logistic analysis results were given to identify the associations between depressive symptoms and each of the individual level variables (including demographic and health-related variables) and environmental control variables. Odds ratios (ORs) and the corresponding 95\% confidence intervals (CIs) were reported. Relations between depression and respondents' characteristics are examined to reflect the representativeness of our sample.

The multilevel logistic regression models to predict depressive symptom were then calculated with individuals nested within cities. The unadjusted model including only the green space indicators was first built, based on which further models controlling for individual level and environmental control variables were constructed to investigate the influence of green space more specifically. The Akaike Information Criterion (AIC) is an estimate of model goodness-of-fit, according to which models that can fit the data with the fewest free parameters are supposed to be the best. The lower the AIC of a model, the better the goodness-of-fit [60]. Descriptive analysis and binary logistic regression analysis were performed in SPSS version 24 (IBM Corp., 2016, Armonk, NY, USA) and the multilevel logistic regression models were performed by Stata version 15 (Stata Corp., 2017, College Station, TX, USA).

\section{Results}

\subsection{Study Sample Characteristics}

A total of 7397 people was included, among which 3814 (51.56\%) people were midaged and $3583(48.44 \%)$ people were elderly. Of these respondents, the mean age was 59.93 $(\mathrm{SD}=10.16)$, and the average CESD-10 score was $7.86(\mathrm{SD}=5.11)$. Table 2 demonstrates the characteristics of the study sample. One-half of the sample were female (51.29\%), and more than $80 \%$ were married or cohabitated (86.97\%). Nearly half of the respondents $(48.65 \%)$ had primary school or below education, and less than a third of the respondents $(22.48 \%)$ had a high school degree or a higher qualification. In total, 2116 (28.61\%) respondents had two or more chronic diseases, and $21.32 \%$ of the respondents had physical function damage. Over four-fifths of the respondents (87.67\%) did not engage in outdoor activity in the last month. An overview of characteristics of the cities is provided in Table 2 as well. The majority of respondents lived in prefecture-level cities (80.52\%). Nearly three-quarters of the respondents (74.64\%) lived in economically less developed cities, and 5118 (69.19\%) respondents lived in cities with relatively sparse population. 
Table 2. Study sample characteristics.

\begin{tabular}{|c|c|c|c|}
\hline Variables & Category & $N$ & $\%$ \\
\hline \multirow{2}{*}{ Age } & $45-60$ & 3814 & 51.56 \\
\hline & $\geq 60$ & 3583 & 48.44 \\
\hline \multirow{2}{*}{ Gender } & Male & 3603 & 48.71 \\
\hline & Female & 3794 & 51.29 \\
\hline \multirow[b]{2}{*}{ Marital Status } & Married and Cohabitated & 6433 & 86.97 \\
\hline & Otherwise & 964 & 13.03 \\
\hline \multirow{4}{*}{ Education level } & Primary education or below & 3599 & 48.65 \\
\hline & Middle school & 2135 & 28.86 \\
\hline & Senior high school & 1197 & 16.18 \\
\hline & Associate degree or above & 466 & 6.30 \\
\hline \multirow{2}{*}{ Work } & Yes & 5630 & 76.11 \\
\hline & No & 1767 & 23.89 \\
\hline \multirow{3}{*}{ Co-morbidity } & No disease & 3528 & 47.70 \\
\hline & Only one disease & 1753 & 23.70 \\
\hline & $\geq$ two diseases & 2116 & 28.61 \\
\hline \multirow{2}{*}{ Physical function damage } & Yes & 1577 & 21.32 \\
\hline & No & 5820 & 78.68 \\
\hline \multirow{2}{*}{ Participation of outdoor activity } & Yes & 912 & 12.33 \\
\hline & No & 6485 & 87.67 \\
\hline \multirow{4}{*}{ City Type } & Municipality Directly under the Central Government & 280 & 3.79 \\
\hline & Vice-provincial City & 769 & 10.40 \\
\hline & Prefecture-level City & 5956 & 80.52 \\
\hline & County-level City & 392 & 5.30 \\
\hline \multirow{3}{*}{ Community city GDP (billion RMB) } & $<500$ & 5521 & 74.64 \\
\hline & $500-1000$ & 1146 & 15.49 \\
\hline & $\geq 1000$ & 730 & 9.87 \\
\hline \multirow{3}{*}{ Population density (persons $/ \mathrm{Km}^{2}$ ) } & $<2500$ & 5118 & 69.19 \\
\hline & $2500-5000$ & 1985 & 26.84 \\
\hline & $\geq 5000$ & 294 & 3.97 \\
\hline
\end{tabular}

\subsection{Binary Analysis of Respondents' Characteristics with Depressive Symptoms}

Almost one-third of all respondents suffered from depressive symptoms (31.20\%). Table 3 illustrates the binary analysis of individual level factors and environmental control factors with depressive symptoms.

For the mid-aged group, the correlates for having a high risk of depressive symptoms were: being female, having had a lower level of education, not married/cohabitated, having chronic diseases, physical function damage, and living in a city with a less developed economy. The correlates for having depressive symptoms in the elderly group slightly differed from those in the mid-aged group. Elderly respondents who have a job, living in a city of a lower administrative level reported higher risk of depression, while marital status did not have a significant effect on depressive symptoms. 
Table 3. ORs ( $95 \% \mathrm{CI})$ of depressive symptoms in relation to individual and environmental factors by age group $(N=7396)$.

\begin{tabular}{|c|c|c|c|}
\hline \multirow{2}{*}{ Variables } & \multirow{2}{*}{ Category } & \multicolumn{2}{|c|}{ Unadjusted OR (95\% CI) } \\
\hline & & Mid-Age Group & Elderly Group \\
\hline \multirow{2}{*}{ Gender } & Male & 1.00 & 1.00 \\
\hline & Female & $2.024(1.758,2.330)^{* * *}$ & $1.744(1.511,2.013)^{* * *}$ \\
\hline \multirow{2}{*}{ Marital status } & Married and Cohabitated & 1.00 & 1.00 \\
\hline & $\begin{array}{c}\text { Separated, Divorced, } \\
\text { Widowed, and Never married }\end{array}$ & $1.496(1.144,1.956)^{* *}$ & $1.144(0.962,1.360)$ \\
\hline \multirow{4}{*}{ Education level } & Primary education or below & 1.00 & 1.00 \\
\hline & Middle school & $0.790(0.673,0.927) *$ & $0.826(0.690,0.989)$ * \\
\hline & Senior high school & $0.666(0.550,0.807)^{* * *}$ & $0.627(0.489,0.804)^{* * *}$ \\
\hline & Associate degree or above & $0.422(0.310,0.575)^{* * *}$ & $0.631(0.437,0.910) *$ \\
\hline \multirow{2}{*}{ Work } & Yes & 1.00 & 1.00 \\
\hline & No & $0.916(0.734,1.143)$ & $0.671(0.578,0.780)^{* * *}$ \\
\hline \multirow{3}{*}{ Co-morbidity } & No disease & 1.00 & 1.00 \\
\hline & Only one disease & $1.354(1.142,1.607) * * *$ & $1.281(1.060,1.548)$ * \\
\hline & $\geq$ two diseases & $1.624(1.363,1.935) * * *$ & $1.883(1.595,2.223)^{* * *}$ \\
\hline \multirow{2}{*}{ Physical function damage } & Yes & 1.00 & 1.00 \\
\hline & No & $0.354(0.288,0.434)^{* * *}$ & $0.478(0.412,0.554)^{* * *}$ \\
\hline \multirow{2}{*}{$\begin{array}{l}\text { Participation of outdoor } \\
\text { activity }\end{array}$} & Yes & 1.00 & 1.00 \\
\hline & No & $0.936(0.765,1.146)$ & $1.045(0.838,1.304)$ \\
\hline \multirow{4}{*}{ City type } & $\begin{array}{l}\text { Municipality Directly under } \\
\text { the Central Government }\end{array}$ & 1.00 & 1.00 \\
\hline & Vice-provincial City & $0.705(0.460,1.082)$ & $1.253(0.794,1.976)$ \\
\hline & Prefecture-level City & $0.952(0.657,1.380)$ & $1.732(1.161,2.853)^{* *}$ \\
\hline & County-level City & $1.342(0.853,2.112)$ & $1.660(1.001,2.754)$ * \\
\hline \multirow{3}{*}{$\begin{array}{c}\text { Community city GDP (Billion } \\
\text { RMB) }\end{array}$} & $<500$ & 1.00 & 1.00 \\
\hline & $500-1000$ & $0.636(0.516,0.784)^{* * *}$ & $0.514(0.414,0.638)^{* * *}$ \\
\hline & $\geq 1000$ & $0.916(0.724,1.159)$ & $0.749(0.588,0.955)$ * \\
\hline \multirow{3}{*}{$\begin{array}{l}\text { Population density (persons / } \\
\qquad \mathrm{Km}^{2} \text { ) }\end{array}$} & $<2500$ & 1.00 & 1.00 \\
\hline & $2500-5000$ & $1.086(0.921,1.086)$ & $1.006(0.848,1.195)$ \\
\hline & $\geq 5000$ & $0.903(0.763,1.068)$ & $1.089(0.918,1.290)$ \\
\hline
\end{tabular}

${ }^{*} p<0.05 ;{ }^{* *} p<0.01 ;{ }^{* * *} p<0.001$.

\subsection{Association between Urban Green Space Indicators with Depressive Symptoms}

Table 4 shows the ORs (95\% CI) of depressive symptoms among the sample population according to the per capita public recreational green space and green coverage area in built up area of city.

Table 4. Results of multilevel logistic models of depressive symptoms by age group.

\begin{tabular}{|c|c|c|c|c|c|c|}
\hline \multirow{3}{*}{ Variables } & \multirow{3}{*}{ Category } & \multirow{2}{*}{$\begin{array}{l}\text { Unadjusted } \\
\text { Model }\end{array}$} & \multicolumn{4}{|c|}{ Adjusted Model } \\
\hline & & & Model 1 & Model 2 & Mode 3 (a) & Model 3 (b) \\
\hline & & \multicolumn{5}{|c|}{ Mid-Aged Group } \\
\hline Per capita public & Low Level & Reference & Reference & Reference & Reference & Reference \\
\hline recreational green & Medium Level & $0.99(0.76,1.29)$ & $1.01(0.78,1.31)$ & $1.04(0.81,1.34)$ & $0.99(0.77,1.27)$ & $1.17(0.84,1.61)$ \\
\hline space $\left(\mathrm{m}^{2} /\right.$ person $)$ & High Level & $1.08(0.72,1.63)$ & $1.07(0.72,1.59)$ & $1.05(0.72,1.54)$ & $1.07(0.73,1.55)$ & $1.39(0.84,2.29)$ \\
\hline Green coverage area & Low Level & Reference & Reference & Reference & Reference & Reference \\
\hline in built up area of city & Medium Level & $0.74(0.58,0.95)$ * & $0.73(0.57,0.93)$ * & $0.73(0.58,0.92) * *$ & $0.79(0.62,0.99)$ * & $0.83(0.65,1.06)$ \\
\hline (hectare $/ \mathrm{Km}^{2}$ ) & High Level & $0.78(0.57,1.07)$ & $0.79(0.58,1.08)$ & $0.79(0.59,1.06)$ & $0.86(0.64,1.15)$ & $1.02(0.71,1.46)$ \\
\hline \multicolumn{2}{|l|}{ AIC } & 4687.427 & 4572.72 & 4503.146 & 4500.684 & 4502.782 \\
\hline
\end{tabular}


Table 4. Cont.

\begin{tabular}{|c|c|c|c|c|c|c|}
\hline \multirow{3}{*}{ Variables } & \multirow{3}{*}{ Category } & \multirow{2}{*}{$\begin{array}{l}\text { Unadjusted } \\
\text { Model }\end{array}$} & \multicolumn{4}{|c|}{ Adjusted Model } \\
\hline & & & Model 1 & Model 2 & Mode 3 (a) & Model 3 (b) \\
\hline & & \multicolumn{5}{|c|}{ Mid-Aged Group } \\
\hline Variables & Category & \multicolumn{5}{|c|}{ Elderly group } \\
\hline Per capita public & Low Level & Reference & Reference & Reference & Reference & Reference \\
\hline recreational green & Medium Level & $0.78(0.59,1.01)$ & $0.76(0.59,0.99)$ * & $0.77(0.59,0.99)$ * & $0.77(0.61,0.99)$ * & $0.82(0.58,1.15)$ \\
\hline space $\left(\mathrm{m}^{2} /\right.$ person $)$ & High Level & $1.40(0.92,2.15)$ & $1.33(0.88,2.03)$ & $1.23(0.81,1.85)$ & $1.16(0.79,1.71)$ & $1.25(0.74,2.09)$ \\
\hline \multirow{3}{*}{$\begin{array}{c}\text { Green coverage area } \\
\text { in built up area of city } \\
\left(\text { hectare } / \mathrm{Km}^{2}\right)\end{array}$} & Low Level & Reference & Reference & Reference & Reference & Reference \\
\hline & Medium Level & $0.67(0.53,0.86)^{* *}$ & $0.66(0.52,0.84)^{* *}$ & $0.70(0.56,0.89)^{* *}$ & $0.75(0.60,0.94) *$ & $0.76(0.60,0.96)$ * \\
\hline & High Level & $0.67(0.49,0.92) *$ & $0.67(0.49,0.92)$ * & $0.71(0.52,0.97) *$ & $0.75(0.57,0.99)$ * & $0.77(0.55,1.09)$ \\
\hline \multicolumn{2}{|l|}{ AIC } & 4419.798 & 4356.739 & 4266.486 & 4255.97 & 4257.827 \\
\hline
\end{tabular}

Model 1: adjusted for demographic factors (i.e., gender, marital status, education level and work); Model 2 : adjusted for model $1+$ health-related factors (i.e., comorbidity, physical function, and outdoor activities); Model 3 (a): adjusted for model 2 + environmental control factors (i.e., city type, city GDP, population density); Model 3 (b): adjusted for Model 3 (a) + interaction of per capita public recreational green space and green coverage area in built up area of city, both interaction variable were not significant, $p$ mid-aged $=0.124>0.05, p$ elderly $=0.706>0.05$; ${ }^{*} p<0.05,{ }^{* *} p<0.01$.

In the unadjusted model, only medium level of green coverage rate was associated with reduced depressive symptoms $(\mathrm{OR}=0.74 ; \mathrm{CI}: 0.58,0.95)$ in the mid-aged group. When green coverage rate increased to medium level, the risk of depression in elderly people was significantly reduced by $33 \%(\mathrm{OR}=0.67$; CI: $0.53,0.86)$. Compared with medium level, high level of green coverage rate did not further significantly reduce depressive symptoms $(\mathrm{OR}=0.67$; CI: $0.49,0.92)$. Per capita public recreational green space was not associated with depressive symptoms in the two age groups.

In Models 1, 2, and 3, potential variables were adjusted relative to the unadjusted model. Adding variables leads to a decrease in AIC scores and thus an improvement in model goodness-of-fit. After adjustment by demographic and health-related variables (Model 2), the per capita public recreational green space was associated with less depressive symptoms of the elderly, with depression reduced by $23 \%$ (OR $=0.77$; CI: $0.59,0.99$ ). However, the effects of coverage rate on depressive symptoms of the mid-aged and elderly both became smaller.

Model 3 (a), a full model controlling for both individual level and environmental control variables to reduce the impact of selection bias, had the lowest AIC and thus the most appropriate model fit.

The positive effects of green space were less salient in mid-aged group. The medium level of the green coverage rate was associated with less depression in the mid-aged group $(\mathrm{OR}=0.79$; CI: $0.62,0.99)$. Per capita public recreational green space, however, was not statistically significant at any level. The risk of depression among the elderly was reduced by $23 \%$ when the per capita public recreational green space reached a medium level $(\mathrm{OR}=0.77$; CI: 0.61, 0.99). Model 3 (a) also indicated that medium level of green coverage rate was significantly associated with a reduction in depression of elderly residents, with depression reduced by $25 \%(\mathrm{OR}=0.75 ; \mathrm{CI}$ : $0.60,0.94)$. A similar result occurred when green coverage rate increased to high level. An interaction term between per capita public recreational green space and green coverage area in built up areas of cities was examined in model 3 (b), which was not significantly associated with depression.

\section{Discussion}

As a result of social and economic development, more than half of the Chinese population now live in urban areas, and the proportion of elderly residents has increased greatly [12-14]. Given that elderly urban residents are at high risk of developing depressive symptoms, more attention should be paid to the mental health status of the ever-increasing aging population in urban areas. Based on a large-scale, nationwide representative survey, this study described depressive symptoms among mid-aged and elderly urban residents in 
China and examined the associated factors. A high prevalence of depressive symptoms was found among Chinese urban residents aged 45 and over, which is consistent with the recent literature on China [7,8] but higher than that in other Asian countries, such as south Korea [11] and Indonesia [9]. The factors relevant to depression differed between the mid-aged and elderly groups in this study.

We found the prevalence of depressive symptoms was higher among women and respondents who lived in a city with a less developed economy. Similar to previous studies, lower education level, having chronic diseases, and physical function damage contributed greatly to depressive symptoms among the mid-aged and the elderly [7,11]. However, this study did not find a significant association between outdoor activity and depressive symptoms, when respondents only reported whether they participated in activities such as dancing and exercising in the last month. Furthermore, marital status was not found to have an influence on depression for the elderly, and employment status as well as the administrative hierarchy of city were not predictors of depressive symptoms for mid-aged people. The exclusion of participants with missing information may help explain why these factors cannot exert influence on the mid-aged and the elderly groups simultaneously.

In recent years, city design has started to focus on promoting elderly-friendly environments where the elderly can have more opportunities to make contact with nature such as green spaces [61-63]. Great emphasis has been made on urban green spaces, which have potential benefits for physical health outcomes, such as weight status and chronic morbidities [64,65]; evidence also indicated a negative association between green space and the impacts of COVID-19 [66,67]. Additionally, green spaces have been consistently found to play an active role in promoting mental health $[11,68,69]$. This study examined whether total green space or specific types of green space were associated with fewer depressive symptoms among mid-aged and elderly urban residents after controlling for individual level factors and environmental control variables.

The green coverage ratio of city-built districts was associated with fewer depressive symptoms among mid-aged and elderly urban residents, which is in accordance with previous studies reporting that the higher the rate of greenery in a city, the less stress and fewer symptoms of depression among its elderly residents [11,70,71]. Increase in urban green spaces is thus encouraged as the urban population is aging. It should be noted that green coverage ratio of city-built districts showed more positive effects in reducing depression in the elderly. Contributors of depression and the corresponding significant influencing factors could differ at different life stages [72]. The influence of environmental factors for the mid-aged may be undermined by other more significant aspects such as socioeconomic status, as they shoulder a heavy burden of work and family support [73,74]. It is interesting that the per capita public recreational green space including park only helped to relieve depressive symptoms for the elderly. A qualitative study showed that larger green spaces were perceived to be better and more attractive than smaller green space, and senior citizens were more likely to use larger green spaces such as parks [40], while the majority of the mid-aged group were still at work and had fewer opportunities to use public recreational green space. Considering that the increase in the total green space can reduce depressive symptoms, further research should investigate the relationship between green spaces in residential and work areas, and depressive symptoms for the midaged. Additionally, the government should also consider establishing appropriate social welfare policies for the elderly to promote them to interact more with public recreational green spaces.

\section{Strengths and Limitations}

This study does have some important strengths. First, owing to a series of strict quality control measures (e.g., global positioning system matching) of CHARLS, the sample in this study was representative of urban mid-aged and elderly residents. Furthermore, different from other studies that focus on high-income countries [75] or megacities such as Beijing [76,77], most respondents in this study lived in prefecture-level cities in China. The 
results can thus help us understand the situation of middle-sized cities and provide practical suggestions for welfare policies in relation to urban green space. Secondly, multilevel analyses were used to account for the relationship between depressive symptoms and provision of green space, which allowed us to identify age-specific patterns of association between green space and depressive symptoms. Moreover, our study makes a supplement to existing studies in this field by first time exploring the impacts of public recreational green space as a specific form of urban green space on depressive symptoms in Chinese cities.

There are also several limitations with this study. First, our study was cross-sectional, which prevents us from drawing causal associations between green space and depression. Second, due to the absence of information on respondents' addresses, respondents' exposure to green space could not be measured precisely in terms of individual residential area. However, official statistics of green space at the city level could be accepted given the common tendency for people to interact with a range of different places in their city. Third, this study only focused on the amount of green space but did not investigate the quality of green space, which could also play an important role in improving mental health [78,79]. Measurement of quality of green space should be included in the future to describe the effects of green space on depression more comprehensively. Fourth, the variable participation of outdoor activity is based on a single question in the CHARLS questionnaire, indicating whether respondents participate in specific activities or not; further research should include variables measuring amount and type of outdoor activities to assess participation of outdoor activity more accurately and comprehensively.

\section{Conclusions}

This study adds insights about the impact of green space and other environmental factors on depressive symptoms among mid-aged and elderly urban dwellers. High green coverage ratio of city-built districts might protect both mid-aged and elderly urban residents against depressive symptoms. Meanwhile, as a specific quantitative indicator, the per capita public recreational green space including park was associated with fewer depressive symptoms among the elderly. These findings may provide empirical evidence for mental health policy-making. Enough and accessible overall urban green space should be provided, and specific type of green spaces such as public recreational green space deserve particular attention; additionally, appropriate social welfare policies and naturebased activities can be developed to promote interaction with existing green resources of urban residents. To deepen the understanding of impacts of green space on mental health and improve green space planning and design, further research exploring impacts of different typologies of green space and the pathways that link green space and mental health is recommended.

Author Contributions: Conceptualization, Y.-J.Z.; formal analysis, R.Z. and Y.-J.Z.; writing-original draft preparation, R.Z. and Y.-J.Z.; writing-review and editing, H.-M.W., R.Z., Y.-J.Z. and J.-Y.Y.; supervision, H.-M.W. All authors have read and agreed to the published version of the manuscript.

Funding: This research received no external funding.

Institutional Review Board Statement: The CHARLS was conducted according to the guidelines of the Declaration of Helsinki, and approved by the Institutional Review Board at Peking University. The ethical approval number was IRB00001052-11015.

Informed Consent Statement: Informed consent was obtained from all subjects involved in the study.

Data Availability Statement: Publicly available datasets were analyzed in this study. This data can be found here: (http:/ / charls.pku.edu.cn/pages/data/2015-charls-wave4/en.html (accessed on 10 December 2019)).

Acknowledgments: The authors are grateful to the China Health and Retirement Longitudinal Study (CHARLS) team for providing data.

Conflicts of Interest: The authors declare no conflict of interest. 


\section{References}

1. World Health Organization. Mental Health and Older Adults. Available online: http://www.who.int/mediacentre/factsheets / fs381/en/ (accessed on 1 March 2020).

2. World Health Organization. Depression and Other Common Mental Disorders. Available online: https://www.who.int/ publications/i/item/depression-global-health-estimates (accessed on 25 December 2021).

3. Min, K.B.; Kim, H.J.; Kim, H.J.; Min, J.Y. Parks and green areas and the risk for depression and suicidal indicators. Int. J. Public Health 2017, 62, 647-656. [CrossRef]

4. World Health Organization. Depression. Available online: http://www.who.int/mediacentre/factsheets/fs369/en/ (accessed on 25 May 2020).

5. Peen, J.; Schoevers, R.A.; Beekman, A.T.; Dekker, J. The current status of urban-rural differences in psychiatric disorders. Acta Psychiatr. Scand. 2010, 121, 84-93. [CrossRef] [PubMed]

6. Zijlema, W.L.; Klijs, B.; Stolk, R.P.; Rosmalen, J.G. (Un)Healthy in the City: Respiratory, Cardiometabolic and Mental Health Associated with Urbanity. PLoS ONE 2015, 10, e0143910. [CrossRef] [PubMed]

7. Lei, X.; Sun, X.; Strauss, J.; Zhang, P.; Zhao, Y. Depressive symptoms and SES among the mid-aged and elderly in China: Evidence from the China Health and Retirement Longitudinal Study national baseline. Soc. Sci. Med. 2014, 120, 224-232. [CrossRef]

8. Wu, Y.; Dong, W.; Xu, Y.; Fan, X.; Su, M.; Gao, J.; Zhou, Z.; Niessen, L.; Wang, Y.; Wang, X. Financial transfers from adult children and depressive symptoms among mid-aged and elderly residents in China-Evidence from the China health and retirement longitudinal study. BMC Public Health 2018, 18, 882. [CrossRef]

9. Majmundar, M.; Smith, J. Aging in Asia: Findings from New and Emerging Data Initiatives, Committee on Policy Research and Data Needs to Meet the Challenge of Aging in Asia; National Research Council, National Academies Press: Washington, DC, USA, 2012.

10. Tao, N.; Yin, P. Research on Risk Factors of Depression and Its Difference between Urban and Rural Middle-aged and Elderly People in China. Chin. J. Soc. Med. 2017, 34, 22-25. [CrossRef]

11. Lee, H.J.; Lee, D.K. Do Sociodemographic Factors and Urban Green Space Affect Mental Health Outcomes Among the Urban Elderly Population? Int. J. Environ. Res. Public Health 2019, 16, 789. [CrossRef] [PubMed]

12. National Bureau of Statistics of China. China Statistical Yearbook; China Statistics Press: Beijing, China, 2019.

13. China Research Center on Aging. Chinese Urban and Rural Elderly Population Status Tracking Survey Report. Available online: http:/ / www.china.com.cn/news/txt/2007-12/17/content_9392818.htm (accessed on 24 March 2020).

14. China Research Center on Aging. Blue Book of Aging: Survey Report on the Living Conditions of China's Urban and Rural Older Persons; Social Science Academic Press: Beijing, China, 2018.

15. Cao, P.Y.; Luo, H.Q.; Hou, L.S.; Yang, X.X.; Ren, X.H. Depressive Symptoms in the Mid-and Old-aged People in China. J. Sichuan Univ. 2016, 47, 763-767. [CrossRef]

16. Zhang, L.; Liu, K.; Li, H.; Li, D.; Chen, Z.; Zhang, L.L.; Guo, L.L. Relationship between body mass index and depressive symptoms: The "fat and jolly" hypothesis for the middle-aged and elderly in China. BMC Public Health 2016, 16, 1201. [CrossRef] [PubMed]

17. Rautio, N.; Filatova, S.; Lehtiniemi, H.; Miettunen, J. Living environment and its relationship to depressive mood: A systematic review. Int. J. Soc. Psychiatry 2018, 64, 92-103. [CrossRef]

18. Simone, C.; Carolin, L.; Max, S.; Reinhold, K. Associations between community characteristics and psychiatric admissions in an urban area. Soc. Psychiatry Psychiatr. Epidemiol. 2013, 48, 1797-1808. [CrossRef] [PubMed]

19. Firdaus, G.; Ahmad, A. Temporal variation in risk factors and prevalence rate of depression in urban population: Does the urban environment play a significant role? Int. J. Ment. Health Promot. 2014, 16, 279-288. [CrossRef]

20. Wang, R.; Yang, B.; Liu, P.; Zhang, J.; Liu, Y.; Yao, Y.; Lu, Y. The longitudinal relationship between exposure to air pollution and depression in older adults. Int. J. Geriatr. Psychiatry 2020, 35, 610-616. [CrossRef] [PubMed]

21. De Vries, S.; Ten Have, M.; Van Dorsselaer, S.; Van Wezep, M.; Hermans, T.; De Graaf, R. Local availability of green and blue space and prevalence of common mental disorders in the Netherlands. BJPsych Open 2016, 2, 366-372. [CrossRef] [PubMed]

22. Kaczynski, A.T.; Henderson, K.A. Environmental correlates of physical activity: A review of evidence about parks and recreation. Leis. Sci. 2007, 29, 315-354. [CrossRef]

23. Maas, J.; van Dillen, S.M.E.; Verheij, R.A.; Groenewegen, P.P. Social contacts as a possible mechanism behind the relation between green space and health. Health Place 2009, 15, 586-595. [CrossRef]

24. Nguyen, P.Y.; Astell-Burt, T.; Rahimi-Ardabili, H.; Feng, X.Q. Green Space Quality and Health: A Systematic Review. Int. J. Environ. Res. Public Health 2021, 18, 11028. [CrossRef]

25. Wood, L.; Hooper, P.; Foster, S.; Bull, F. Public green spaces and positive mental health-Investigating the relationship between access, quantity and types of parks and mental wellbeing. Health Place 2017, 48, 63-71. [CrossRef]

26. Fan, Y.L.; Das, K.V.; Chen, Q. Neighborhood green, social support, physical activity, and stress: Assessing the cumulative impact. Health Place 2011, 17, 1202-1211. [CrossRef]

27. Astell-Burt, T.; Feng, X.Q. Association of Urban Green Space with Mental Health and General Health Among Adults in Australia. JAMA Netw. Open 2019, 2, e198209. [CrossRef]

28. Kabisch, N.; Van Den Bosch, M.; Lafortezza, R. The health benefits of nature-based solutions to urbanization challenges for children and the elderly-A systematic review. Environ. Res. 2017, 159, 362-373. [CrossRef] [PubMed] 
29. Gascon, M.; Sanchez-Benavides, G.; Dadvand, P.; Martinez, D.; Gramunt, N.; Gotsens, X.; Cirach, M.; Vert, C.; Molinuevo, J.L.; Crous-Bou, M.; et al. Long-term exposure to residential green and blue spaces and anxiety and depression in adults: A cross-sectional study. Environ. Res. 2018, 162, 231-239. [CrossRef] [PubMed]

30. Kim, J.H.; Lee, C.; Sohn, W. Urban Natural Environments, Obesity, and Health-Related Quality of Life among Hispanic Children Living in Inner-City Neighborhoods. Int. J. Environ. Res. Public Health 2016, 13, 121. [CrossRef] [PubMed]

31. Bezold, C.P.; Banay, R.F.; Coull, B.A.; Hart, J.E.; James, P.; Kubzansky, L.D.; Missmer, S.A.; Laden, F. The Association Between Natural Environments and Depressive Symptoms in Adolescents Living in the United States. J. Adolesc. Health 2018, 62, $488-495$. [CrossRef]

32. Dadvand, P.; Hariri, S.; Abbasi, B.; Heshmat, R.; Qorbani, M.; Motlagh, M.E.; Basagana, X.; Kelishadi, R. Use of green spaces, self-satisfaction and social contacts in adolescents: A population-based CASPIAN-V study. Environ. Res. 2019, 168, 171-177. [CrossRef] [PubMed]

33. Dzhambov, A.; Hartig, T.; Markevych, I.; Tilov, B.; Dimitrova, D. Urban residential greenspace and mental health in youth: Different approaches to testing multiple pathways yield different conclusions. Environ. Res. 2018, 160, 47-59. [CrossRef]

34. Hipp, J.A.; Gulwadi, G.B.; Alves, S.; Sequeira, S. The Relationship Between Perceived Greenness and Perceived Restorativeness of University Campuses and Student-Reported Quality of Life. Environ. Behav. 2016, 48, 1292-1308. [CrossRef]

35. Holt, E.W.; Lombard, Q.K.; Best, N.; Smiley-Smith, S.; Quinn, J.E. Active and Passive Use of Green Space, Health, and Well-Being amongst University Students. Int. J. Environ. Res. Public Health 2019, 16, 424. [CrossRef]

36. Yang, T.; Barnett, R.; Fan, Y.; Li, L. The effect of urban green space on uncertainty stress and life stress: A nationwide study of university students in China. Health Place 2019, 59, 102199. [CrossRef]

37. Grazuleviciene, R.; Vencloviene, J.; Kubilius, R.; Grizas, V.; Dedele, A.; Grazulevicius, T.; Ceponiene, I.; Tamuleviciute-Prasciene, E.; Nieuwenhuijsen, M.J.; Jones, M.; et al. The Effect of Park and Urban Environments on Coronary Artery Disease Patients: A Randomized Trial. BioMed Res. Int. 2015, 2015, 403012. [CrossRef]

38. Grazuleviciene, R.; Vencloviene, J.; Kubilius, R.; Grizas, V.; Danileviciute, A.; Dedele, A.; Andrusaityte, S.; Vitkauskiene, A.; Steponaviciute, R.; Nieuwenhuijsen, M.J. Tracking Restoration of Park and Urban Street Settings in Coronary Artery Disease Patients. Int. J. Environ. Res. Public Health 2016, 13, 550. [CrossRef] [PubMed]

39. Boers, S.; Hagoort, K.; Scheepers, F.; Helbich, M. Does Residential Green and Blue Space Promote Recovery in Psychotic Disorders? A Cross-Sectional Study in the Province of Utrecht, The Netherlands. Int. J. Environ. Res. Public Health 2018, 15, 2195. [CrossRef] [PubMed]

40. Macintyre, V.G.; Cotterill, S.; Anderson, J.; Phillipson, C.; Benton, J.S.; French, D.P. “I Would Never Come Here Because I've Got My Own Garden": Older Adults' Perceptions of Small Urban Green Spaces. Int. J. Environ. Res. Public Health 2019, 16, 1994. [CrossRef] [PubMed]

41. Peeters, G.; Van Gellecum, Y.R.; Van Uffelen, J.G.Z.; Burton, N.W.; Brown, W.J. Contribution of house and garden work to the association between physical activity and well-being in young, mid-aged and older women. Br. J. Sports Med. 2014, 48, 996-1001. [CrossRef] [PubMed]

42. Ayabe, M.; Yahiro, T.; Yoshioka, M.; Higuchi, H.; Higaki, Y.; Tanaka, H. Objectively Measured Age-Related Changes in the Intensity Distribution of Daily Physical Activity in Adults. J. Phys. Act. Health 2009, 6, 419-425. [CrossRef] [PubMed]

43. Villanueva, K.; Pereira, G.; Knuiman, M.; Bull, F.; Wood, L.; Christian, H.; Foster, S.; Boruff, B.J.; Beesley, B.; Hickey, S.; et al. The impact of the built environment on health across the life course: Design of a cross-sectional data linkage study. BMJ Open 2013, 3, e002482. [CrossRef] [PubMed]

44. Colley, K.; Currie, M.J.B.; Irvine, K.N. Then and Now: Examining Older People's Engagement in Outdoor Recreation Across the Life Course. Leis. Sci. 2019, 41, 186-202. [CrossRef]

45. Freeman, C.; Waters, D.L.; Buttery, Y.; Van Heezik, Y. The impacts of ageing on connection to nature: The varied responses of older adults. Health Place 2019, 56, 24-33. [CrossRef]

46. Li, C.; Liu, T.; Sun, W.; Wu, L.; Zou, Z.Y. Prevalence and risk factors of arthritis in a middle-aged and older Chinese population: The China health and retirement longitudinal study. Rheumatology 2015, 54, 697-706. [CrossRef]

47. Wen, Y.; Liu, C.J.; Liao, J.; Yin, Y.Q.; Wu, D.M. Incidence and risk factors of depressive symptoms in 4 years of follow-up among mid-aged and elderly community-dwelling Chinese adults: Findings from the China Health and Retirement Longitudinal Study. BMJ Open 2019, 9, e029529. [CrossRef]

48. Andresen, E.M.; Malmgren, J.A.; Carter, W.B.; Patrick, D.L. Screening for depression in well older adults-Evaluation of a short-form of the CES-D. Am. J. Prev. Med. 1994, 10, 77-84. [CrossRef]

49. Chen, H.J.; Mui, A.C. Factorial validity of the Center for Epidemiologic Studies Depression Scale short form in older population in China. Int. Psychogeriatr. 2014, 26, 49-57. [CrossRef] [PubMed]

50. Ministry of Housing and Urban-Rural Development of the People's Republic of China. 2015 China Urban Construction Statistical Yearbook; China Statistics Press: Beijing, China, 2016.

51. Mukherjee, D.; Safraj, S.; Tayyab, M.; Shivashankar, R.; Patel, S.A.; Narayanan, G.; Ajay, V.S.; Ali, M.K.; Narayan, K.V.; Tandon, N.; et al. Park availability and major depression in individuals with chronic conditions: Is there an association in urban India? Health Place 2017, 47, 54-62. [CrossRef] [PubMed]

52. Astell-Burt, T.; Mitchell, R.; Hartig, T. The association between green space and mental health varies across the lifecourse. A longitudinal study. J. Epidemiol. Community Health 2014, 68, 578-583. [CrossRef] 
53. Reklaitiene, R.; Grazuleviciene, R.; Dedele, A.; Virviciute, D.; Vensloviene, J.; Tamosiunas, A.; Baceviciene, M.; Luksiene, D.; Sapranaviciute-Zabazlajeva, L.; Radisauskas, R.; et al. The relationship of green space, depressive symptoms and perceived general health in urban population. Scand. J. Public Health 2014, 42, 669-676. [CrossRef]

54. Kroc, L.; Socha, K.; Soltysik, B.K.; Cieslak-Skubel, A.; Piechocka-Wochniak, E.; Blaszczak, R.; Kostka, T. Validation of the Vulnerable Elders Survey-13 (VES-13) in hospitalized older patients. Eur. Geriatr. Med. 2016, 7, 449-453. [CrossRef]

55. Song, M.N.; Cheng, X.; Kong, J.X.; Wang, H.M. Prevalence and influencing factors of overweight and obesity among middle-aged and elderly people in China. Chin. J. Dis. Control Prev. 2018, 22, 804-808. [CrossRef]

56. Wang, X.J. Analysis of problems in urban green space system planning in China. J. For. Res. 2009, 20, 79-82. [CrossRef]

57. Chen, W.Y.; Hu, F.Z.Y. Producing nature for public: Land-based urbanization and provision of public green spaces in China. Appl. Geogr. 2015, 58, 32-40. [CrossRef]

58. Richards, D.R.; Passy, P.; Oh, R.R.Y. Impacts of population density and wealth on the quantity and structure of urban green space in tropical Southeast Asia. Landsc. Urban Plan. 2017, 157, 553-560. [CrossRef]

59. Ma, L.J.C. Urban administrative restructuring, changing scale relations and local economic development in China. Political Geogr. 2005, 24, 477-497. [CrossRef]

60. Akaike, H. A New Look at The Statistical Model Identification. IEEE Trans. Autom. Control 1974, 19, 716-723. [CrossRef]

61. World Health Organization. Global Age-Friendly Cities: A Guide. Switzerland: Geneva Press. Available online: https: / / www.who.int/ageing/age_friendly_cities_guide/en/ (accessed on 25 March 2020).

62. World Health Organization. Global Health and Aging; USA Press: New York, NY, USA, 2011

63. Wen, C.; Albert, C.; Von Haaren, C. The elderly in green spaces: Exploring requirements and preferences concerning nature-based recreation. Sustain. Cities Soc. 2018, 38, 582-593. [CrossRef]

64. Sander, H.A.; Ghosh, D.; Hodson, C.B. Varying age-gender associations between body mass index and urban greenspace. Urban For. Urban Green. 2017, 26, 1-10. [CrossRef] [PubMed]

65. Dennis, M.; Cook, P.A.; James, P.; Wheater, C.P.; Lindley, S.J. Relationships between health outcomes in older populations and urban green infrastructure size, quality and proximity. BMC Public Health 2020, 20, 626. [CrossRef] [PubMed]

66. Roviello, V.; Roviello, G.N. Lower COVID-19 mortality in Italian forested areas suggests immunoprotection by Mediterranean plants. Environ. Chem. Lett. 2021, 19, 699-710. [CrossRef]

67. Roviello, V.; Roviello, G.N. Less COVID-19 deaths in southern and insular Italy explained by forest bathing, Mediterranean environment, and antiviral plant volatile organic compounds. Environ. Chem. Lett. 2021. [CrossRef]

68. Orr, N.; Wagstaffe, A.; Briscoe, S.; Garside, R. How do older people describe their sensory experiences of the natural world? A systematic review of the qualitative evidence. BMC Geriatr. 2016, 16, 116. [CrossRef]

69. Silva, R.A.; Rogers, K.; Buckley, T.J. Advancing Environmental Epidemiology to Assess the Beneficial Influence of the Natural Environment on Human Health and Well-Being. Environ. Sci. Technol. 2018, 52, 9545-9555. [CrossRef] [PubMed]

70. Astell-Burt, T.; Feng, X.Q.; Kolt, G.S. Mental health benefits of neighbourhood green space are stronger among physically active adults in middle-to-older age: Evidence from 260,061 Australians. Prev. Med. 2013, 57, 601-606. [CrossRef]

71. Wu, Y.T.; Prina, A.M.; Jones, A.; Matthews, F.E.; Brayne, C. Older people, the natural environment and common mental disorders: Cross-sectional results from the Cognitive Function and Ageing Study. BMJ Open 2015, 5, e007936. [CrossRef]

72. Madva, E.N.; Gomez-Bernal, F.; Millstein, R.A.; Celano, C.M.; Park, E.R.; Mastromauro, C.A.; Albanese, A.M.; Beale, E.E.; Huffman, J.C. Magnitude and sources of distress in mid-life adults with chronic medical illness: An exploratory mixed-methods analysis. Psychol. Health Med. 2018, 23, 555-566. [CrossRef] [PubMed]

73. Kim, J.W. Different roles of social participation in socioeconomic disparities in depressive symptoms of Koreans across age groups. J. Public Health-Heidelb. 2021. [CrossRef]

74. Dainese, S.M.; Allemand, M.; Ribeiro, N.; Bayram, S.; Martin, M.; Ehlert, U. Protective factors in midlife: How do people stay healthy? GeroPsych J. Gerontopsychol. Geriatr. Psychiatry 2011, 24, 19-29. [CrossRef]

75. Van Den Bosch, M.; Ode Sang, Å. Urban natural environments as nature-based solutions for improved public health-A systematic review of reviews. Environ. Res. 2017, 158, 373-384. [CrossRef]

76. Helbich, M.; Yao, Y.; Liu, Y.; Zhang, J.; Liu, P.; Wang, R. Using deep learning to examine street view green and blue spaces and their associations with geriatric depression in Beijing, China. Environ. Int. 2019, 126, 107-117. [CrossRef]

77. Zhu, Y.; Ding, J.; Zhu, Q.; Cheng, Y.; Ma, Q.; Ji, X. The Impact of Green Open Space on Community Attachment-A Case Study of Three Communities in Beijing. Sustainability 2017, 9, 560. [CrossRef]

78. Van Dillen, S.M.E.; de Vries, S.; Groenewegen, P.P.; Spreeuwenberg, P. Greenspace in urban neighbourhoods and residents' health: Adding quality to quantity. J. Epidemiol. Community Health 2012, 66, e8. [CrossRef] [PubMed]

79. Francis, J.; Wood, L.J.; Knuiman, M.; Giles-Corti, B. Quality or quantity? Exploring the relationship between Public Open Space attributes and mental health in Perth, Western Australia. Soc. Sci. Med. 2012, 74, 1570-1577. [CrossRef] [PubMed] 